\title{
Author Correction: Selective Inhibition of Succinate Dehydrogenase in Reperfused Myocardium with Intracoronary Malonate Reduces Infarct Size
}

\author{
Laura Valls-Lacalle ${ }^{1,2}$, Ignasi Barba ${ }^{1,2}$, Elisabet Miró-Casas ${ }^{1,2}$, Marisol Ruiz-Meana ${ }^{1,2}$, \\ Antonio Rodríguez-Sinovas $\mathbb{D}^{1,2}$ \& David García-Dorado ${ }^{1,2}$
}

Correction to: Scientific Reports https://doi.org/10.1038/s41598-018-20866-4, published online 05 February 2018

The original version of this Article contained an error in Affiliation 1, which was incorrectly given as 'Cardiovascular Diseases Research Group, Department of Cardiology, Vall d'Hebron University Hospital and Research Institute, Universitat Autònoma de Barcelona, Barcelona, Spain'. The correct affiliation is listed below:

Cardiovascular Diseases Research Group, Department of Cardiology, Vall d'Hebron University Hospital and Research Institute, Universitat Autònoma de Barcelona, Departament de Medicina, Barcelona, Spain.

This error has now been corrected in the HTML and PDF versions of the Article and in the accompanying Supplementary Figures file.

(i) Open Access This article is licensed under a Creative Commons Attribution 4.0 International License, which permits use, sharing, adaptation, distribution and reproduction in any medium or format, as long as you give appropriate credit to the original author(s) and the source, provide a link to the Creative Commons license, and indicate if changes were made. The images or other third party material in this article are included in the article's Creative Commons license, unless indicated otherwise in a credit line to the material. If material is not included in the article's Creative Commons license and your intended use is not permitted by statutory regulation or exceeds the permitted use, you will need to obtain permission directly from the copyright holder. To view a copy of this license, visit http://creativecommons.org/licenses/by/4.0/.

(c) The Author(s) 2019

${ }^{1}$ Cardiovascular Diseases Research Group, Department of Cardiology, Vall d'Hebron University Hospital and Research Institute, Universitat Autònoma de Barcelona, Departament de Medicina, Barcelona, Spain. ${ }^{2}$ Centro de Investigación Biomédica en Red Enfermedades Cardiovasculares (CIBERCV), Instituto de Salud Carlos III, Madrid, Spain. Correspondence and requests for materials should be addressed to A.R.-S. (email: antonio.rodriguez. sinovas@vhir.org) or D.G.-D. (email:dgdorado@vhebron.net) 